\title{
85305 - DECLÍNIO COGNITIVO COMO FATOR DE RISCO PARA INFECÇÃO DO TRATO URINÁRIO EM IDOSOS INSTITUCIONALIZADOS
}

\author{
Pôster - Gerontologia
}

\author{
Ingrid Araújo Ribeiro / Ribeiro, IA / UESC; \\ João Luis Almeida da Silva / Silva, JLA / UESC; \\ Dulce Aparecida Barbosa / Barbosa, DA / UNIFESP
}

Introdução: as doenças crônicas não transmissíveis são as mais prevalentes entre os idosos; porém a fragilização por doenças infecciosas constitui importante intercorrência clínica, motivo de internações e óbito. Entre as mais comuns está a do trato urinário, pois os idosos estão propensos à presença de vários fatores de risco, entre eles, a institucionalização, idade avança e declínio cognitivo (ARAUJO, 2011; ANDRADE et al, 2017). Objetivo: avaliar o declínio cognitivo de idosos institucionalizados e sua associação com Infecção do Trato Urinário (ITU). Métodos: estudo transversal, recorte do Projeto: Avaliação do Impacto de Intervenção Educacional na Prevalência de Infecção do Trato Urinário em Idosos Institucionalizados; CEP-UESC no. 1.050.366. População:116 idosos institucionalizados, período: junho a dezembro de 2017. Avaliação: resultados de urocultura e aplicação do Mini Exame do Estado Mental (MEEM). Resultados: maioria com 80 anos ou mais $(36,2 \%)$; sexo feminino $(65,52 \%)$; $84,79 \%$ com grau de comprometimento cognitivo $(65,52 \%$ grave); MEEM médio: 12,45/30 pontos; 88,6\% analfabetos. Regressão logística e testes estatísticos demonstraram significância entre tempo de estudo e déficit cognitivo ( $p$ value $<0,001$ ), mas não houve associação de declínio cognitivo com ITU ( $\mathrm{p}$ value $=0,55$ ). Conclusão: quanto menor a instrução educacional maior o risco de declínio cognitivo, corroborando com a literatura (ANDRADE et al, 2017; MELO e BARBOSA, 2015). No contexto estudado, déficit cognitivo não se apresentou como fator de risco para ITU, sugerindo mais estudos com associação a outros fatores integrados. A utilização do MEEM possibilitou traçar metas e estratégias para uma melhor assistência à população idosa no intuito de reduzir a progressão da perda cognitiva e encaminhamentos de casos à avaliação neurológica.

Palavras-chave: Instituição de Longa Permanência para Idosos, Envelhecimento cognitivo, Sistema Urinário.

Referências: 1. ARAÚJO, R.A. Estudo dos factores de risco associados a infecções do tracto urinário em idosos institucionalizados. Portugal. Dissertação [Mestrado] - Universidade da Beira Interior. 2011. 121 p.; 2. ANDRADE, F.L.J.P. et al. Incapacidade cognitiva e fatores associados em idosos institucionalizados. Revista Brasileira de Geriatria e Gerontologia. v. 20, n. 2, p. 186-197, 2017; 3. MELO, D.M; BARBOSA, A.J.G. O uso do MEEM em pesquisas com idosos no Brasil: uma revisão sistemática. Ciência e Saúde Coletiva. v. 20, n. 12, p. 3865-3876, 2015. 